\title{
ОЦІНКА РІВНЯ ФІЗИЧНОЇ ПІДГОТОВЛЕНОСТІ УЧНІВ МОЛОДШИХ КЛАСІВ ЗАГАЛЬНООСВІТНЬОЇ ШКОЛИ
}

\author{
Спіцин В.В. \\ Харківський національний педагогічний університет імені Г.С. Сковороди
}

DOI: $10.17309 /$ tmfv.2014.4.1116

\begin{abstract}
Анотація. У статті аналізується проблема системного управління оцінкою рівня фізичної підготовленості дітей молодшого шкільного віку. Встановлено, що вірна оцінка рівня фізичної підготовленості є одним з важливих факторів підвищення ефективності керування процесом фізичного виховання учнів загальноосвітньої школи, починаючи з першого класу. Аналіз результатів дослідження свідчить, що при систематичному спостереженні за руховою підготовленістю кожного окремого учня, дозволяє учителю фізичної культури вчасно спостерігати картину розвитку рухових якостей та навичок, виявляти ті, що відстають, та на основі диференційованого підходу, за допомогою спеціальних педагогічних впливів, досягати необхідного ефекту в рішенні завдань фізичного виховання дітей молодшого шкільного віку.

Учитель фізичної культури загальноосвітньої школи, у процесі своєї трудової діяльності, здійснюючи систематичний педагогічний контроль за руховою підготовленістю школярів та проводячи аналіз результатів контролю, при цьому знаючи динаміку розвитку основних рухових якостей, може якісно керувати процесом фізичного вихованням учнів, починаючи з першого класу.

Ключові слова: засоби, фізична підготовка, фізична культура, фізичне виховання, урок.
\end{abstract}

Актуальність. На даний час в Україні склалася критична ситуація за станом здоров'я серед учнів молодших класів. За даними Міністерства охорони здоров'я України близько 70\% дітей мають різні відхилення у стані здоров'я, а 59\% - незадовільну фізичну підготовленість. 3 кожним роком різко збільшується кількість учнів, яких за станом здоров’я відносять до спеціальної медичної групи. Серед найбільш розповсюджених захворювань переважають хвороби органів дихання (до 50\%) i часті повторні гострі респіраторно-вірусні захворювання (ГРВ3) (до 85\%), що є свідченням зниження опірності дитячого організму до несприятливих умов навколишнього середовища.

Слід зазначити, що економічні та політичні негаразди в Україні значно змістили акценти у виховній галузі, в результаті чого проблеми фізичного виховання віддалилися на останній план. Сучасна школа, у зв'язку з надмірною насиченістю навчальних програм, слабким фінансуванням, ще не може успішно здійснювати процес фізичного виховання учнів.

Як відомо, що недостатня рухова активність учнів молодших класів є однією з причин порушення постави, появи надлишкової ваги та інших порушень у фізичному розвитку. Крім цього, недостатня рухова активність знижує функціональні можливості серцево-судинної і дихальної систем дітей, внаслідок чого появляються порушення неадекватної реакції серця на навантаження, зменшується життєва ємність легень. Аналіз стану фізичного виховання учнів молодших класів України свідчить,

(с) Спіцин В.В., 2014. що у більшості з них традиційно не формується потреба піклуватись про стан власного здоров'я.

Важливо визначити, що останніми роками з'явилась така думка, що роботу з фізичної культури у загальноосвітній школі треба оцінювати не тільки по спортивним результатам, що показані юними спортсменами на змаганнях, а ще оцінювати постановку фізичного виховання в школі за даними фізичної підготовленості всіх учнів, їх стану здоров’я і фізичного розвитку, починаючи з першого класу. У зв'язку з цим, збереження і зміцнення здоров'я дітей, формування духовних потреб і навичок здорового способу життя повинні бути пріоритетними напрямками розвитку нашого суспільства.

Аналіз останніх досліджень і публікацій. Науковий пошук свідчить, що на сьогодні проблема фізичного виховання дітей в Україні досліджувалась у роботах Вільчковського Е.С. (1998), Круцевич Т.Ю. (2012), Кузнецової 3.І. (2000), Леськіва А.Д. (1997) та інших науковців. Автори зробили висновок, що для організму, який росте потрібно застосовувати оздоровчі програми, які спрямовані на підвищення можливостей дитячого організму з метою покращення фізичного стану молодших школярів і зміцнення здоров'я підростаючого покоління.

Відзначимо, що проблемі фізичної підготовки та вікового розвитку фізичних якостей школярів присвячені роботи Гужаловского А.А. (1978), Кузнецової 3. І. (1999), Шияна Б.М. (2002), Матвєєва Л.П. (2004), Худолій О.М., Іващенко О.В. (2014) та інших фахівців у галузі фізичної культури, які вважають, що рухова підготовленість є важливим компонен- 
том здоров’я учнів, а ії поліпшення - однієї з головних завдань фізичного виховання в школі. Для доцільної та ефективної організації занять з фізичної культури, визнають науковці, необхідно мати повну інформацію про рівень фізичної підготовленості школярів на кожному етапі навчання, починаючи 3 першого класу. Наявність цієї інформації, особливо на етапі формування рухових функцій, має велике практичне значення. Тому оцінка ефективності фізичного виховання в школі повинна вираховуватись з одного боку, за станом здоров'я учнів, а з іншого боку - за рівнем розвитку основних фізичних якостей, тобто за рівнем фізичної підготовленості учнів.

Отже, суспільна значущість та актуальність розв'язання окресленої проблеми зумовили вибір теми дослідження: «Оцінка рівня фізичної підготовленості учнів молодших класів загальноосвітньої школи».

\section{Матеріал і методи.}

Мета дослідження полягає в обгрунтуванні доцільності використання методу оцінки рівня фізичної підготовленості учнів молодших класів загальноосвітньої школи протягом навчального року. Завдання дослідження:

1. Обгрунтувати значення педагогічного контролю за оцінкою рівня фізичної підготовленістю учнів молодших класів загальноосвітньої школи протягом навчального року.

2. Визначити рівень розвитку фізичних якостей учнів 3-го класу.

3. Виявити й узагальнити динаміку фізичної підготовленості учнів 3-го класу, протягом навчального року.

Об'єкт дослідження - система фізичної підготовленості школярів на уроках фізичної культури у загальноосвітній школі.

Предмет дослідження - впровадження педагогічного контролю за оцінкою рівня фізичної підготовленості учнів молодших класів загальноосвітньої школи.

Практичне значення одержаних результатів полягає в тому, що дослідження актуалізує педагогічні ідеї щодо вирішення проблем організації фізичної підготовленості школярів молодших класів загальноосвітньої школи, що може стати в пригоді при вирішенні проблем щодо впровадження змісту, форм і методів організації фізичного виховання підростаючого покоління.

Запропонована нами система педагогічного контролю за динамікою фізичної підготовленості учнів молодших класів на уроках фізичної культури може використовуватися не лише у процесі організованих занять із фізичного виховання в школі, а й самостійно.

Також, розроблені нами належні норми фізичної підготовленості учнів молодших класів можуть стати модельно-цільовими характеристиками фі- зичного стану для програмування фізичного виховання школярів на уроках та позаурочних заняттях.

Методи дослідження. Для отримання об'єктивної інформації відповідно до визначених завдань у роботі використовувалися наступні методи дослідження:

- метод аналізу науково-методичної та спеціальної літератури;

- метод тестування (контрольні випробування);

- метод математико-статистичної обробки отриманих даних.

Організація дослідження. Дослідження проводилося протягом 2013-2014 н.р. та складалося із трьох етапів.

На першому етапі дослідження, нами було зроблено аналіз науково-методичної та спеціальної літератури по проблемі, що досліджувалася: анатомо-фізіологічні та психологічні особливості дітей молодшого шкільного віку; фізична підготовка як складова частина процесу фізичного виховання дітей молодшого шкільного віку; організація педагогічного контролю за фізичною підготовленістю учнів молодших класів у загальноосвітній школі; навчальний матеріал та методичні рекомендації 3 фізичної культури для 3 класу загальноосвітньої школи.

Як свідчить науковий пошук, що організація фізичного виховання учнів молодших класів загальноосвітньої школи як науково-педагогічна проблема полягає в створенні фундаменту для всебічного фізичного розвитку, зміцнення здоров'я, формування різноманітних рухових умінь і навичок, що приводить до виникнення об'єктивних передумов для гармонійного розвитку особистості.

Другий етап нашого дослідження було присвячено визначенню рівня розвитку рухових якостей у школярів молодших класів. Для контрольних випробувань було використано п'ять рухових тестів на визначення рівня розвитку різних фізичних якостей, а саме:

- швидкості - біг $30 \mathrm{M}$;

- витривалості - змішане пересування (біг чергуючи з ходьбою) на дистанцію до 1100 м;

- гнучкості - нахил тулуба вперед із положення сидячи ;

- сили - підтягування у висі лежачи;

- спритності - «човниковий» біг $4 \times 9$ м;

- швидкісно-силових якостей - стрибок у довжину з місця поштовхом двох ніг.

У дослідженні взяли участь учні 3-го класу (10 хлопчиків та 10 дівчаток) НВК «Авторська школа Бойка» м. Харкова. Всі вони систематично займалися фізичними вправами на уроках фізичної культури два рази на тиждень, які передбачені шкільною програмою (Т. Круцевич, 2012), із дозволу шкільно- 
ISSN 1993-7989 (print). ISSN 1993-7997 (online). Теорія та методика фізичного виховання. 2014. № 04

Таблиия 1

Результати початкового та підсумкового тестувань фбізичної підготовленості учнів 3-го класу

\begin{tabular}{|c|c|c|c|c|c|c|c|c|c|c|c|c|}
\hline \multirow{3}{*}{$\begin{array}{l}\text { № } \\
3 / \Pi\end{array}$} & \multicolumn{12}{|c|}{ ПОКАЗНИКИ } \\
\hline & \multicolumn{2}{|c|}{ Біг 30 м (сек.) } & \multicolumn{2}{|c|}{$\begin{array}{c}\text { Змішане пере- } \\
\text { сування до } 1100 \text { м } \\
\text { (м) }\end{array}$} & \multicolumn{2}{|c|}{$\begin{array}{c}\text { Нахил тулуба } \\
\text { вперед із по- } \\
\text { ложення сидячи } \\
\text { (см) }\end{array}$} & \multicolumn{2}{|c|}{$\begin{array}{c}\text { Підтягування у висі } \\
\text { лежачи (разів) }\end{array}$} & \multicolumn{2}{|c|}{$\begin{array}{c}\text { Човниковий біг } \\
\text { 4x9 м } \\
\text { (сек.) }\end{array}$} & \multicolumn{2}{|c|}{$\begin{array}{c}\text { Стрибок у до- } \\
\text { вжину } 3 \text { місця } \\
\text { (см) }\end{array}$} \\
\hline & $\begin{array}{c}\text { Bepe- } \\
\text { сень }\end{array}$ & $\begin{array}{l}\text { Кві- } \\
\text { тень }\end{array}$ & $\begin{array}{c}\text { Вере- } \\
\text { сень }\end{array}$ & $\begin{array}{l}\text { Кві- } \\
\text { тень }\end{array}$ & $\begin{array}{c}\text { Bере- } \\
\text { сень }\end{array}$ & $\begin{array}{l}\text { Кві- } \\
\text { тень }\end{array}$ & $\begin{array}{c}\text { Bере- } \\
\text { сень }\end{array}$ & $\begin{array}{l}\text { Кві- } \\
\text { тень }\end{array}$ & $\begin{array}{c}\text { Вере- } \\
\text { сень }\end{array}$ & $\begin{array}{l}\text { Кві- } \\
\text { тень }\end{array}$ & $\begin{array}{c}\text { Вере- } \\
\text { сень }\end{array}$ & $\begin{array}{l}\text { Кві- } \\
\text { тень }\end{array}$ \\
\hline \multicolumn{13}{|c|}{ Хлопчики } \\
\hline 1. & 6,4 & 6,2 & 1100 & 1100 & 1 & 2 & 10 & 12 & 12,0 & 11,8 & 109 & 110 \\
\hline 2. & 6,5 & 6,2 & 1100 & 1100 & 1 & 3 & 8 & 11 & 12,5 & 12,4 & 106 & 108 \\
\hline 3. & 7,5 & 7,4 & 920 & 1100 & 0,5 & 2 & 7 & 10 & 14,1 & 14,0 & 92 & 98 \\
\hline 4. & 6,0 & 5,8 & 1100 & 1100 & 1 & 4 & 13 & 17 & 11,8 & 11,6 & 112 & 114 \\
\hline 5. & 6,5 & 6,4 & 1100 & 1100 & 2 & 3 & 14 & 15 & 13,3 & 13,1 & 107 & 110 \\
\hline 6. & 7,0 & 6,8 & 1100 & 1100 & 1 & 2 & 11 & 14 & 13,8 & 13,5 & 104 & 107 \\
\hline 7. & 6,6 & 6,3 & 1100 & 1100 & 3 & 4 & 14 & 17 & 13,0 & 12,9 & 110 & 112 \\
\hline 8. & 6,8 & 6,4 & 1100 & 1100 & 1 & 2 & 12 & 14 & 13,2 & 13,0 & 107 & 110 \\
\hline 9. & 6,1 & 6,0 & 1100 & 1100 & 4 & 4,5 & 15 & 19 & 12,2 & 12,1 & 116 & 117 \\
\hline 10. & 6,9 & 6,5 & 1100 & 1100 & 1 & 3 & 11 & 13 & 13,4 & 13,2 & 103 & 106 \\
\hline \multicolumn{13}{|c|}{ Дівчатка } \\
\hline 1. & 7,5 & 7,4 & 860 & 1100 & 2 & 3 & 3 & 5 & 14,8 & 14,5 & 82 & 88 \\
\hline 2. & 6,9 & 6,7 & 1100 & 1100 & 3 & 5 & 7 & 8 & 13,8 & 13,6 & 96 & 99 \\
\hline 3. & 7,4 & 7,3 & 1100 & 1100 & 3 & 4 & 6 & 8 & 13,8 & 13,7 & 91 & 93 \\
\hline 4. & 7,0 & 7,0 & 1100 & 1100 & 3 & 4 & 8 & 10 & 13,5 & 13,5 & 93 & 95 \\
\hline 5. & 6,8 & 6,7 & 1100 & 1100 & 4 & 5 & 10 & 11 & 13,7 & 13,6 & 97 & 98 \\
\hline 6. & 7,2 & 7,0 & 1100 & 1100 & 5 & 6 & 7 & 9 & 13,9 & 13,7 & 92 & 96 \\
\hline 7. & 7,1 & 7,0 & 1100 & 1100 & 2 & 4 & 7 & 9 & 13,6 & 13,5 & 94 & 96 \\
\hline 8. & 7,4 & 7,1 & 1100 & 1100 & 2 & 3 & 9 & 10 & 14,0 & 13,8 & 92 & 97 \\
\hline 9. & 7,8 & 7,5 & 1020 & 1100 & 2 & 3 & 8 & 11 & 14,3 & 14,1 & 89 & 92 \\
\hline 10. & 6,6 & 6,2 & 1100 & 1100 & 4 & 6 & 11 & 14 & 13,0 & 12,8 & 104 & 105 \\
\hline
\end{tabular}

го лікаря. Прийом контрольних вправ здійснювалося два рази: початкове тестування на початку навчального року - для визначення вихідного рівня фізичної підготовленості учнів 3 класу; підсумкове тестування - у кінці навчального року, для визначення змін у фізичній підготовленості дітей за цей період (табл. 1).

На третьому етапі, на основі використання методу математико-статистичної обробки отриманих даних, нами було виявлено у школярів 3-го класу рівні розвитку основних рухових якостей та їх динаміки росту, протягом навчального року (табл. 2).

Як свідчить науковий пошук, що у хлопчиків статистично достовірний приріст $(\mathrm{p}<0,05)$ показників виявлено у «човниковому» бігу $4 \mathrm{x} 9$ м, де були зафіксовані наступні результати: 12,93 сек. \pm 0,17 сек. та 12,76 сек. $\pm 0,17$ сек., що характеризують рівень розвитку спритності та швидкості (школа пересувань), та у змішаному пересуванні на дистанцію до 1100 м, де були зафіксовані наступні результати: $1082 \mathrm{~m} \pm 12,70 \mathrm{м}$ та $1100 \mathrm{~m} \pm 0,00 \mathrm{м}$, що характеризують рівень розвитку загальної витривалості (школа пересувань).

Зауважимо, що результати, які показали хлопчики в бігу на 30 м, що характеризують рівень розвитку швидкості; нахилах тулуба вперед із положення сидячи, що характеризують рівень розвитку гнучкості (школа культури рухів); в підтягуванні у висі лежачи, що характеризують рівень розвитку сили (школа сприяння розвитку фізичних здатностей); в стрибках у довжину з місця, що характеризують рівень розвитку швидкісно-силових якостей м'язів ніг (школа стрибків) - змінились убік поліпшення результатів, але вони виявились статистично не достовірними ( $\mathrm{p}>0,05)$. 
Показники динаміки змін основних рухових якостей школярів 3-го класу протягом навчального року

\begin{tabular}{|c|c|c|c|c|c|}
\hline \multirow[b]{2}{*}{ № } & \multirow[b]{2}{*}{ Тести } & \multicolumn{4}{|c|}{ ПОКАЗНИКИ } \\
\hline & & $\begin{array}{c}\text { Початкові } \\
\mathrm{X} \pm \mathrm{s}\end{array}$ & $\begin{array}{c}\text { Підсумкові } \\
\text { X } \pm s\end{array}$ & $\begin{array}{c}\text { Приріст, } \\
\text { \% }\end{array}$ & $\mathrm{p}$ \\
\hline \multicolumn{6}{|c|}{ Хлопчики } \\
\hline 1 & Біг 30 м (сек.) & $6,63 \pm 0,01$ & $6,4 \pm 0,099$ & 3,5 & $>0,05$ \\
\hline 2 & Змішане пересування до 1100 м (м) & $1082 \pm 12,7$ & $1100 \pm 0,00$ & 1,6 & $<0,05$ \\
\hline 3 & $\begin{array}{l}\text { Нахил тулуба вперед із положення си- } \\
\text { дячи (см) }\end{array}$ & $1,55 \pm 0,25$ & $2,95 \pm 0,21$ & 90,3 & $<0,05$ \\
\hline 4 & Підтягування у висі лежачи (раз) & $11,50 \pm 0,59$ & $14,20 \pm 0,64$ & 23,4 & $>0,05$ \\
\hline 5 & «Човниковий» біг 4x9 м (сек.) & $12,93 \pm 0,17$ & $12,76 \pm 0,17$ & 1,4 & $>0,05$ \\
\hline 6 & Стрибок у довжину з місця (см) & $106,6 \pm 1,43$ & $109,2 \pm 1,15$ & 2,4 & $>0,05$ \\
\hline \multicolumn{6}{|c|}{ Дівчатка } \\
\hline 1 & Біг 30 м (сек.) & $7,17 \pm 0,08$ & $6,99 \pm 0,09$ & 2,6 & $>0,05$ \\
\hline 2 & Змішане пересування до 1100 м (м) & $1068 \pm 17,29$ & $1100 \pm 0,00$ & 3,0 & $<0,05$ \\
\hline 3 & $\begin{array}{l}\text { Нахил тулуба вперед із положення си- } \\
\text { дячи (см) }\end{array}$ & $3,0 \pm 0,24$ & $4,3 \pm 0,26$ & 43,3 & $<0,05$ \\
\hline 4 & Підтягування у висі лежачи (раз) & $7,6 \pm 0,50$ & $9,5 \pm 0,53$ & 25 & $>0,05$ \\
\hline 5 & «Човниковий» біг 4x9 м (сек.) & $13,84 \pm 0,11$ & $13,68 \pm 0,10$ & 1,2 & $>0,05$ \\
\hline 6 & Стрибок у довжину з місця (см) & $93 \pm 1,27$ & $95,9 \pm 1,05$ & 3,1 & $>0,05$ \\
\hline
\end{tabular}

У дівчаток, так само як і у хлопчиків, відбулися позитивні зміни в показниках за усіма тестами. Однак, статистично достовірні $(\mathrm{p}<0,05)$ зміни результатів спостерігалися, тільки у «човниковому» бігу 4x9 м, де були зафіксовані наступні результати: 13,84 сек. $\pm 0,11$ сек. та 13,68 сек. $\pm 0,10$ сек., що характеризують рівень розвитку спритності та швидкості (школа пересувань), та у змішаному пересуванні на дистанцію до 1100 м, де були зафіксовані наступні результати: $1068 \mathrm{~m} \pm 17,29$ м та $1100 \mathrm{M} \pm$ 0,00 м, що характеризують рівень розвитку загальної витривалості (школа пересувань).

Зауважимо, що результати, які показали дівчатка в бігу на 30 м, що характеризують рівень розвитку швидкості; нахилах тулуба вперед із положення сидячи, що характеризують рівень розвитку гнучкості (школа культури рухів); в підтягуванні у висі лежачи, що характеризують рівень розвитку сили (школа сприяння розвитку фізичних здатностей); в стрибках у довжину з місця, що характеризують рівень розвитку швидкісно-силових якостей м'язів ніг (школа стрибків) - змінились убік поліпшення результатів, але вони виявились статистично не достовірними ( $\mathrm{p}>0,05)$.

Обговорення результатів дослідження. Наведені результати дослідження доповнюють дані Гужаловського А.А. (1978), Волкова Л.В. (1981), Вільчковського Е.С. (1998), Кузнецової 3.І. (2000), Худолія О.М., Іващенко О.В., Черненко С.О. (2013),
Худолія О.М., Іващенко О.В. $(2013,2014)$ про цілісність процесів розвитку рухових здібностей і формування рухових навичок у школярів молодших класів.

Данні нашого дослідження співпадають з думками фахівців з фізичного виховання, у тому, що змістом предмету «Фізична культура» у початковій школі є рухова активність із загальнорозвивальною спрямованістю, де значення набуває виховання життєво важливих фізичних якостей: спритності, витривалості, сили, швидкості, гнучкості, а також уміння довільно розслаблювати м’язи.

\section{Висновки}

1. Аналіз спеціальної літератури дозволяє сказати, що фахівці фізичної культури та спорту вважають однієї з головних завдань фізичного виховання в загальноосвітній школі підвищення рівня фізичної підготовленості школярів, починаючи з молодших класів. Для рішення цієї та інших, не менш важливих завдань фізичного виховання, необхідно проводити систематичний педагогічний контроль та його аналіз. Оцінювання фізичної підготовки учнів, починаючи з перших класів, за показниками приросту індивідуальних результатів, дозволяє створити у школярів позитивний психологічний настрой та спонукає їх домагатись ще більше ви- 
сокого рівня фізичної підготовленості, протягом усього періоду навчання в школі.

2. Проведене дослідження показало, що планування навчальної роботи з фізичного виховання у загальноосвітній школі повинне здійснюватися протягом усього періоду навчання в школі, з урахуванням сенситивних періодів розвитку фізичних якостей, які притаманні кожній віковій групі.

3. Спираючись на результати дослідження, ми бачимо, що в учнів молодших класів, як у хлопчи- ків, так і у дівчаток, протягом навчального року відбулися позитивні зрушення за усіма розглянутими нами тестами. Однак, статистично достовірні зміни відзначені тільки в «човниковому» бігу та в змішаному пересуванні.

Перспективи подальших досліджень. Надалі вважаємо за логічне продовжити дослідження оцінкою рівня фізичної підготовленості учнів середніх та старших класів.

\section{Література}

1. Вільчковський Е.С. Система фізичного виховання молодших школярів. Навчально-методичний посібник. - К.: ІЗМН, 1998. - 232 с.

2. Волков Л.В. Физические способности детей и подростков. - Киев: Здоров'я, 1981. - 76 с.

3. Гужаловский А.А. Развитие двигательных качеств у школьников. - Мн.: Нар. асвета, 1978. - 88 с.

4. Круцевич Т.Ю. Навчальна програма з фізичної культури для загальноосвітніх навчальних закладів. 1-4 класи [Електронний ресурс] / Т.Ю. Круцевич, Л.М. Кузьомко, С.Г. Приймак, П.Б. Кондратенко. - К., 2012. - Режим доступу: http://fizkulturamo. at.ua/load/programmy_po_fizkulture/mladshaja_ shkola/1_4_klasi_zagalnoosvitnikh_navchalnikh_ zakladiv/9-1-0-66

5. Кузнецова 3.И. Как вести контроль за двигательной подготовленностью школьников // Физкультура в школе. -2000 . - № $1 .-72$ с.

6. Кузьомко Л.М. Фізична підготовленість учнів загальноосвітніх шкіл [Електронний ресурс] / Л.М. Кузьомко, С.Г. Приймак, П.Б. Кондратенко. - Режим доступу: http://archive.nbuv.gov.ua/portal/ Soc_Gum/ppmb/texts/2007-08/07klmuos.pdf.

7. Леськів А.Д. Форми і засоби фізичного виховання молодших школярів: Методичний посібник / Леськів А.Д., Андрощук Н.В., Мехоношин С.О., Дзюбановський А.Б. - Тернопіль “Астон”, 1997. - 108 с.

8. Лях В.И. Тесты в физическом воспитании школьников: Пособие для учителя. - М., ООО «Фирмаиздательство АСТ», 1998. - 54 с.

9. Матвеев Л.П. Теория и методика физической культуры: Учебник для высших специальных физкультурных учебных заведений. - СПб.: Изд-во «Лань», М.: ООО Изд-во «Омега-Л», 2004 - 160 с.

10. Сухарев А.Г. Состояние здоровья школьников и факторы его формирования /А.Г. Сухарев // Гигиена и санитария. - 1982. - №5. - С.70-72.

11. Худолій О.М., Чинники, що впливають на ефективність навчання фізичним вправам хлопчиків молодших класів / Худолій О.М., Іващенко О.В., Черненко С.О. // Теорія та методика фізичного виховання. - 2013. - № 1. - C. 21-26. DOI: http:// dx.doi.org/10.17309/tmfv.2013.1.1006

12. Худолій О. М. Технологія навчання гімнастичним вправам / О. М. Худолій // Теорія та методика фі-

\section{References}

1. Vil'chkovs'kyy E.S. (1998). Systema fizychnoho vykhovannya molodshykh shkolyariv. Navchal'nometodychnyy posibnyk. K.: IZMN, 232.

2. Volkov L.V. (1981). Fizicheskie sposobnosti detey i podrostkov. Kiev: Zdorov'ya, 76.

3. Guzhalovskiy A.A. (1978). Razvitie dvigatelnyih kachestv u shkolnikov. Mn.: Nar. asveta, 88.

4. Krutsevych T.Yu., Kuz’omko L.M., Pryymak S.H. \& Kondratenko P.B. (2012). Navchal'na prohrama z fizychnoyi kul'tury dlya zahal'noosvitnikh navchal'nykh zakladiv. 1-4 klasy [Elektronnyy resurs], K. - Rezhym dostupu: http://fizkulturamo.at.ua/load/programmy_ po_fizkulture/mladshaja_shkola/1_4_klasi_ zagalnoosvitnikh_navchalnikh_zakladiv/9-1-0-66

5. Kuznetsova Z.I. (2000). Kak vesti kontrol za dvigatelnoy podgotovlennostyu shkolnikov. Fizkultura v shkole, (1), 72.

6. Kuz'omko L.M., Pryymak S.H. \& Kondratenko P.B. (2007). Fizychna pidhotovlenist' uchniv zahal'noosvitnikh shkil [Elektronnyy resurs]. Rezhym dostupu: http://archive.nbuv.gov.ua/portal/ Soc_Gum/ppmb/texts/2007-08/07klmuos.pdf.

7. Les'kiv A.D., Androshchuk N.V., Mekhonoshyn S.O. \& Dzyubanovs'kyy A.B. (1997). Formy i zasoby fizychnoho vykhovannya molodshykh shkolyariv: Metodychnyy posibnyk. Ternopil' "Aston", 108.

8. Lyah V.I. (1998). Testyi v fizicheskom vospitanii shkolnikov: Posobie dlya uchitelya. M., OOO «Firmaizdatelstvo ACT», 54.

9. Matveev L.P.(2004). Teoriya i metodika fizicheskoy kulturyi: Uchebnik dlya vyisshih spetsialnyih fizkulturnyih uchebnyih zavedeniy. SPb.: Izd-vo «Lan», M.: OOO Izd-vo «Omega-L», 160.

10. Suharev A.G. (1982). Sostoyanie zdorovya shkolnikov i faktoryi ego formirovaniya. Gigiena i sanitariya, (5), 70-72.

11. Khudolii O.M., Ivashchenko O.V., \& Chernenko S.O. (2013). Chinniki, scho vplivayut na efektivnist navchannya fizichnim vpravam hlopchikiv molodshih klasiv. Teoria ta metodika fizicnogo vihovanna [Theory and methods of the physical education], (1), 21-26. DOI:http://dx.doi.org/10.17309/tmfv.2013.1.1006

12. Khudoliy O. M. (2009). Tekhnolohiya navchannya himnastychnym vpravam. Teoria ta metodika fizicnogo vihovanna [Theory and methods of the 
зичного виховання. - 2009. - № 9. - С. 19-34. DOI:http://dx.doi.org/10.17309/tmfv.2009.9.562

13. Худолій О.М., Концептуальні підходи до моделювання процесу навчання і розвитку рухових здібностей у дітей і підлітків / Худолій О.М., Іващенко О.В. // Теорія та методика фізичного виховання. - 2013. - № 2. - C. 3-16. DOI: http://dx.doi. org/10.17309/tmfv.2013.2.1012

14. Худолій О.М. Моделювання процесу навчання та розвитку рухових здібностей у дітей і підлітків: Монографія / Худолій О.М., Іващенко О.В. - Харків: ОВС, 2014. - 320 c.

15. Цвек С.Ф. Фізичне виховання молодших школярів. - К: “Радянська школа”, 1986. - 123 с.

16. Шиян Б.М. Теорія і методика фізичного виховання школярів: підручник: в 2ч. / Б.М. Шиян.- Тернопіль: Навчальна книга-Богдан, 2002. - Ч.1. - 272 с. physical education], (9), 19-34. - DOI:http://dx.doi. org/10.17309/tmfv.2009.9.562

13. Khudolii O. M., \& Ivashchenco O. V. (2013). Kontseptualni pidhodi do modelyuvannya protsesu navchannya i rozvitku ruhovih zdibnostey u ditey i pidlitkiv. Teoria ta metodika fizicnogo vihovanna [Theory and methods of the physical education], (10), 3-16. DOI: http://dx.doi.org/10.17309/tmfv.2013.2.1012

14. Khudolii O. M., \& Ivashchenco O. V. (2014). Modelyuvannya protsesu navchannya ta rozvitku ruhovih zdibnostey u ditey i pidlitkiv: Monografiya. Kharkiv: OVS, 320.

15. Tsvek S.F. (1986). Fizychne vykhovannya molodshykh shkolyariv. K: "Radyans'ka shkola”, 123.

16. Shyyan B.M. (2002). Teoriya i metodyka fizychnoho vykhovannya shkolyariv: pidruchnyk: v $2 \mathrm{ch}$. Ternopil': Navchal'na knyha-Bohdan, 1, 272 c.

\title{
ОЦЕНКА УРОВНЯ ФИЗИЧЕСКОЙ ПОДГОТОВЛЕННОСТИ УЧАЩИХСЯ МЛАДШИХ КЛАССОВ ОБЩЕОБРАЗОВАТЕЛЬНОЙ ШКОЛЫ
}

\author{
Спицин В.B. \\ Харьковский национальный педагогический университет имени Г. С. Сковороды
}

Реферат. Статья: 6 с., 2 табл., 16 источников.

В статье анализируется проблема системного управления оценивания уровня физической подготовленности детей младшего школьного возраста. Установлено, что верная оценка уровня физической подготовленности является одним из важных факторов повышения эффективности управления процессом физического воспитания учащихся общеобразовательной школы, начиная с первого класса. Анализ результатов исследования свидетельствует, что при систематическом наблюдении за двигательной подготовленностью каждого отдельного ученика, позволяет учителю физической культуры контролировать развитие двигательных качеств и навыков учеников, выявлять отстающие, и на основе дифференцированного подхода, с помощью специальных педа- гогических воздействий, достигать необходимого эффекта в решении задач физического воспитания детей младшего школьного возраста.

Учитель физической культуры общеобразовательной школы, в процессе своей трудовой деятельности, осуществляя систематический педагогический контроль за двигательной подготовленностью школьников и проводя анализ результатов контроля, при этом зная динамику развития основных двигательных качеств, может качественно управлять процессом физического воспитанием учащихся, начиная с первого класса.

Ключевые слова: средство, физическая подготовка, физическая культура, физическое воспитание, урок.

\section{EVALUATION OF THE LEVEL OF PHYSICAL PREPARATION OF PUPILS OF JUNIOR SECONDARY SCHOOL}

\author{
Spitsin V.V. \\ G.S. Skovoroda Kharkiv National Pedagogical University \\ Report. Article: 6 p., 2 tabl., 16 sources
}

The article analyzes the problem of system management estimates the level of physical preparedness of children of primary school age. It is established that the correct assessment of the level of physical fitness is one of the important factors increasing the efficiency of management of process 
of physical training of students of secondary schools, starting from the first grade. Analysis of results of investigation shows, that systematic monitoring of motor preparedness of each individual student, allows the teacher of physical culture monitor the development of motor skills and skills of the pupils identify lagging, and based on a differentiated approach, with special educational impacts, to achieve a desired effect in solving the problems of physical education of children of younger school age.
The teacher of physical culture secondary school, in the course of his career, carrying out systematic pedagogical monitoring of the motor skills of pupils and conducting analysis of the control results, knowing dynamics of development of main motor skills, can efficiently manage the process of the physical training of students, starting from the first grade.

Key words: tool, physical training, physical culture, physical education, lesson.

\section{Інформація про авторів:}

Спіцин B.B.: spitsin.vitaly@yandex.ua; Харківський національний педагогічний університет імені Г.С. Сковороди, вул. Артема, 29, м. Харків, 61002, Україна.

Цитуйте статтю як: Спіцин В.В. Оцінка рівня фізичної підготовленостіучнів молодшихкласівзагальноосвітньої школи / Спіцин В.В.// Теорія та методика фізичного виховання. - 2014. - № 4. - C. 38-44. DOI: http://dx.doi. org/10.17309/tmfv.2014.4.1116

Стаття надійшла до редакції: 05.11.2014 р. Прийнята: 15.12.2014 р. Надрукована: 25.12.2014 p. 